\title{
Supply Chain Coordination with Two-Part Tariffs under Information Asymmetry
}

\author{
Chongqi $\mathrm{Wu}$ \\ California State University, East Bay, Department of Management \\ Kunpeng Li \\ California State University, Northridge, Department of Systems and Operations Management \\ Tianqin Shi \\ San Jose State University, School of Global Innovation and Leadership
}

\begin{abstract}
Supply chain coordination literature indicates that two-part tariff contracts cannot coordinate a supply chain with a supplier and a retailer under information asymmetry, but can coordinate the channel under full information, while leaving the retailer zero profit. Motivated by the practice of Costco Business Centers, we incorporate customer heterogeneity, near-saturated retail market, and asymmetric information into a stylized model. The retailer has the knowledge of customer heterogeneity while the supplier does not. The supplier, on the other hand, designs a menu of two-part tariffs for the retailer to choose from. We have found that two-part tariffs can coordinate the supply chain under asymmetric information, while leaving the retailer a positive profit. In addition, a one-size-fits-all two-part tariff can coordinate the supply chain at equilibrium, i.e., there is no need for the supplier to design different two-part tariffs for the retailer who may possess different types of information.
\end{abstract}

Keywords: Supply Chain Coordination, Supply Chain Management, Two-Part Tariffs, Adverse Selection, Information Asymmetry

\section{Introduction}

A two-part tariff contract is a pricing scheme in which a seller charges a buyer a fixed fee and a unit price. In general, the unit price decreases as more units are purchased, which is also known as quantity discount. A two-part tariff with a constant unit price is called a two-part linear tariff. Unless otherwise specified, a two-part tariff refers to a two-part linear tariff in this paper. Two-part tariffs are commonly observed in retail markets as well as in wholesale markets. In retail markets, examples include Costco or Sam's Club membership, museums and zoos, and access to some website information, among many others (Vettas, 2011). In wholesale markets, an upstream firm (hereafter denoted as the "supplier" or "she") often charges a downstream firm (hereafter denoted as the "retailer" or "he") a lump sum for the 
right to carry her products plus a constant unit price. For example, the prevalent licensing agreement usually specifies a fixed fee along with a royalty for each unit (San Martin and Saracho, 2015). Another example in wholesale markets is that a credit card company charges merchants a per-transaction fee plus a fixed fee (Reisinger, 2014).

Supply chain coordination literature indicates that a two-part tariff contract cannot coordinate a supply chain of bilateral monopoly with a supplier and a retailer under information asymmetry (Wang et al. 2012). While under full information, Corbett et al. (2004) demonstrated that two-part tariffs can coordinate a supply chain with one manufacturer and one retailer. To achieve coordination, the manufacturer would choose a unit price equal to her marginal cost and a fixed fee equal to the total profit that a vertically integrated monopolist would have. However, it has a rather unrealistic effect: the retailer obtains zero profit. To overcome this unrealistic effect, Corbett et al. (2004) turned to the retailer's outside opportunity for explanation. The outside opportunity guarantees the retailer a positive reservation profit level.

As highlighted above, despite its popularity, a two-part tariff generally fails to coordinate supply chain coordination under information asymmetry and results in zero profit under full information for a retailer without external opportunity. Therefore, in this article, we ask the following questions: under information asymmetry, can two-part tariffs coordinate the channel and leave the retailer positive profit, even if the retailer has no external opportunity? In other words, is it possible that the positive profit of the retailer can be an endogenous outcome at equilibrium in which the supply chain is also coordinated?

To answer the above questions, this paper considers a stylized two-echelon supply chain with one supplier and one retailer. The supplier is a Stackelberg leader who designs a menu of two-part tariff contracts. The retailer is a Stackelberg follower who decides whether to accept a contract and which contract to accept. The retailer will accept a contract if and only if he receives non-negative profit under this contract. If the retailer accepts a contract, then he sets the retail price. The retailer faces a market modeled as a linear city with a uniform distribution of consumers. A customer's utility is dependent on the retail price and the cost of travelling to the retailer. A customer will buy one unit of the product if s/he receives non-negative utility. The utility function results in such a demand function: if the retail price is sufficiently low, then the entire market is served or saturated and the price elasticity of market demand becomes zero; if the retail price is sufficiently high, then the market demand decreases in retail price and the market is unsaturated. This demand function captures a realistic aspect of market demand that many other demand functions do not have: the market can and will be saturated if the price is sufficiently low. As will be shown later in the paper, this aspect actually helps the retailer fight for a reasonable profit in a supplier-dominated supply chain without sacrificing channel coordination. If the supplier gets too greedy, the retailer can raise the retail price correspondingly. At the tipping price point between a saturated 
market and an unsaturated one, an increase in retail price will hurt the profit of the supplier more than that of the retailer. In addition, similar to Çakanyıldırım et al. (2012), information asymmetry is introduced into the model: the supplier does not know the exact value of the unit transportation cost, while the retailer does. Using an adverse selection model to capture the information asymmetry, this paper shows that the retailer facing low transportation cost can leverage his market knowledge advantage over the supplier to obtain a positive profit at equilibrium where the channel coordination is also achieved.

A motivation of our stylized model is Costco Business Centers (not the regular Costco warehouse), which aim at small business owners like those who operate restaurants, food trucks, and convenience stores. The products available at Costco Business Centers include staples and dry goods, fresh and frozen meats, produce, other food products, candy, gum, cigarettes, soft drinks, snacks, beer and wine, office supplies, etc. Costco charges business members a membership fee in addition to unit price. While Costco appears dominant over its small business members, these small business owners have information advantage regarding their customers. It is not worthwhile for Costco to investigate the small market that each small business serves. Small business owners can leverage their information advantage over the powerful Costco for reasonable profit.

The key contribution of the paper is that it provides an alternative explanation to the prevalent two-part tariffs in practice. To the best of our knowledge, the existing supply chain coordination literature has the following relevant findings: (1) under full information, two-part tariffs can coordinate supply chains but leave the retailer zero profit if the retailer has no external opportunity; (2) under information asymmetry, two-part tariffs cannot coordinate supply chains. Motivated by Costco Business Centers, we incorporate customer heterogeneity, near-saturated retail market, and asymmetric information into a stylized model. The retailer has the knowledge of customer heterogeneity while the supplier does not. The supplier, on the other hand, designs a menu of two-part tariffs for the retailer to choose from. We have found that two-part tariffs can coordinate the supply chain under asymmetric information, while leaving the retailer a positive profit. In addition, a one-size-fits-all two-part tariff can coordinate the supply chain at equilibrium, i.e., there is no need for the supplier to design different two-part tariffs for the retailer who may possess different types of information.

The rest of the paper is organized as follows. We first review related literature in Section 2. In Section 3, the models under fully information and under information asymmetry are introduced. Section 4 presents the model results and insights. Summary of the paper is provided in Section 5.

\section{Relation to Literature}


A large number of supply chain management studies have been focused on contracting issues (for an excellent review, see Cachon 2003, Swaminathan et al. 2003, Huang et al. 2003, Chan et al. 2010), because supply chain contracts are effective tools to coordinate supply chains by eliminating double marginalization. Examples of such contracts include, among others, buyback contracts (Pasternack, 1985), revenue-sharing contracts (Cachon and Lariviere, 2005), quantity flexibility contracts (Tsay, 1999), and quantity discount contracts (Weng, 1995). Some literature presents scenarios that supply chain can be coordinated through contracts. Sabbaghi et al. (2007) found that wholesale price contracts can coordinate the channel when the manufacturer is capacity-constrained, with the retail price exogenously given. Hematyar et al. (2014) found that rebate contracts can achieve supply chain coordination when the retailer is a newsvendor facing price dependent stochastic demand. Our paper builds upon this stream of literature by specifically examining when two-part tariffs can coordinate a supply chain under asymmetric information.

A more relevant stream of literature studies supply chain coordination with two-part tariffs under full information. Two-part tariffs have been advocated as a way to coordinate a supply chain (Zusman and Etgar, 1981). Moorthy (1987) argued that a two-part tariff can motivate the retailer to set the channelprofit maximizing price in a decentralized channel. Agrawal and Seshadri (2000) considered a two-part tariff contract that coordinates a risk-averse retailer and a risk-neutral distributor. A two-part tariff can not only increase order quantity of the retailers to the optimal level, but also maximize the distributor's expected profit. Chen and Yang (2014) found that reinforcement/punishment contracts with a two-part tariff can perfectly coordinate a supply chain in which the production of the primary supplier is subject to random yield and the buyer has an emergency backup sourcing. In particular, Corbett et al. (2004) concluded that two-part tariffs can coordinate a two-echelon supply chain under full information. However, the retailer would receive zero profit if he does not have external opportunity. Corbett et al. (2004) also looked into two-part tariffs under asymmetric information, which will be discussed later.

Supply chain coordination under asymmetric information has also been modeled in literature (Ha 2001, Zhang 2010). In most of these literatures, adverse selection models have been adopted. The principals design a menu of contracts. The agents, typically with information advantage over the principals, select the contracts that benefit them the most. Focusing on buyback contracts, Babich et al. (2012) considered a model of asymmetric demand information in which the retailer possesses private information about the demand distribution. They found that the supplier's optimal buyback contract leads to the first-best solution with the supplier keeping the entire channel's profit. In a two-echelon supply chain where the retailer is modeled as a newsvendor, Wang et al. (2012) concluded that a retailerimplemented two-part tariff, in which the retailer charges an upfront lump sum fee when he does not know the manufacturer's unit production cost, performs substantially better than many commonly used 
contracts. This retailer-implemented two-part tariff contract, however, is unable to coordinate the supply chain. In a setting with demand risk where the retailer has hidden information on service level, Lutze and Ozer (2008) found that a promised lead-time contract benefits both the supplier and the retailer in risk sharing. In addition, under information asymmetry where the supplier does not know the retailer's cost structure, Corbett et al. (2004) found that two-part tariffs cannot coordinate the supply chain.

Table 1 summarizes some key similarities and differences in major assumptions between our work and the relevant papers.

Table 1: Key Similarities and Differences in Model Assumptions

\begin{tabular}{|l|l|l|l|l|}
\hline & Information & Contract Type & Demand & Channel Structure \\
\hline $\begin{array}{l}\text { Wang et al. } \\
(2012)\end{array}$ & Symmetric & $\begin{array}{l}\text { Retailer-implemented } \\
\text { two-part tariffs }\end{array}$ & Deterministic & $\begin{array}{l}\text { One supplier one } \\
\text { retailer }\end{array}$ \\
\hline $\begin{array}{l}\text { Moorthy } \\
(1987)\end{array}$ & Symmetric & Two-part tariffs & Deterministic & $\begin{array}{l}\text { One supplier one } \\
\text { retailer }\end{array}$ \\
\hline $\begin{array}{l}\text { Chen and } \\
\text { Yang }(2014)\end{array}$ & Symmetric & $\begin{array}{l}\text { Reinforcement/punish } \\
\text { ment contracts with } \\
\text { two-part tariff }\end{array}$ & Stochastic & $\begin{array}{l}\text { One supplier, one } \\
\text { buyer with backup } \\
\text { sourcing }\end{array}$ \\
\hline $\begin{array}{l}\text { Corbett et al. } \\
(2004)\end{array}$ & $\begin{array}{l}\text { Symmetric and } \\
\text { asymmetric }\end{array}$ & $\begin{array}{l}\text { Two-part tariffs and } \\
\text { other contracts }\end{array}$ & Deterministic & $\begin{array}{l}\text { One supplier one } \\
\text { retailer }\end{array}$ \\
\hline $\begin{array}{l}\text { Babich et al. } \\
(2012)\end{array}$ & Asymmetric & Buyback & Stochastic & $\begin{array}{l}\text { One supplier one } \\
\text { retailer }\end{array}$ \\
\hline $\begin{array}{l}\text { Chen et al. } \\
(2012)\end{array}$ & Symmetric & Two-part tariffs & Deterministic & $\begin{array}{l}\text { Dual channel; one } \\
\text { supplier with direct } \\
\text { channel and retailer }\end{array}$ \\
\hline This work & Asymmetric & Two-part tariffs & Deterministic & $\begin{array}{l}\text { One supplier one } \\
\text { retailer }\end{array}$ \\
\hline
\end{tabular}

As shown in Table 1, our work is most closely related to Corbett et al. (2004) in terms of key assumptions. As noted earlier, in Corbett et al. (2004), two-part tariffs can coordinate a supplier-retailer channel but leave the retailer zero profit under full information; and two-part tariffs cannot coordinate the supply chain with asymmetric information. By introducing heterogeneous customers and near-saturated market into the model, we contribute to the existing literature on supply chain coordination with two-part tariffs with the following findings: (1) two-part tariffs can coordinate a supplier-retailer supply chain even under asymmetric information; (2) the retailer may receive positive profit at equilibrium when the supply chain is coordinated without turning to external opportunities; and (3) under certain conditions, it is not necessary for the supplier to differentiate the types of the retailer and one two-part tariff designed for all types may coordinate the supply chain as well. 


\section{Models}

In this section, we present our models, first a base model under full information, then the model under information asymmetry.

\subsection{The Base Model under Full Information}

Consider a two-echelon supply chain with one supplier $S$, and one retailer $R$. The retailer faces a market modeled as a linear city on the interval $[0,1]$ with density 1 . Consumers are distributed uniformly along this interval. The retailer is located in the middle of the linear city at $1 / 2$. This assumption can be relaxed by allowing the retailer to be located at the end point, and our qualitative results will continue to hold. The supply chain dynamics are modeled as a two-stage Stackelberg game. First, the supplier determines the terms of the two-part tariff supply contract $(w, F)$, where $w$ is the unit wholesale price and $F$ is the franchise fee or membership fee. After knowing the terms of the supply contract, the retailer chooses his retail price, $p$. The marginal costs of producing or selling one unit of product is normalized to zero for simplicity.

A consumer who is located at $1 / 2-x($ or $1 / 2+x)$ receives a utility of $1-p-t x$, where 1 is the reservation price of all potential consumers, $t$ is the unit transportation cost, and $x$ is the distance from this consumer to the retail store. Therefore, a customer at $x=(1-p) / t$ receives zero utility. The resulting demand function of the retailer is as follows:

$$
q=\left\{\begin{array}{ccc}
1 & \text { if } & p \leq 1-t / 2 \\
2(1-p) / t & \text { if } & 1-t / 2 \leq p \leq 1
\end{array}\right.
$$

This demand function captures the scenario of saturated or near-saturated market, which is a focal point of this work. A similar but more complicated demand function can be seen in Yang et al. (2010). To investigate the manufacturer's optimal mail-in rebate decision in the face of the retailer' ability to raise price, Yang et al. (2010) derived the demand model from the consumer's utility which depends on the manufacturer's rebate, the manufacturer's suggested retail price, as well as the actual retail price.

Conditional on the contract $(w, F)$, the retailer sets optimal retail price to maximize his profit, $Y_{R}$.

$$
\operatorname{Max}_{p} Y_{R}=(p-w) q-F
$$

The optimal retail price as a function of the wholesale price $w$ can be easily derived from the first-order condition of the maximization problem in (2):

$$
p^{*}=\left\{\begin{array}{clc}
1-t / 2 & \text { if } & w \leq 1-t \\
(1+w) / 2 & \text { if } & 1-t \leq w \leq 1
\end{array}\right.
$$

The resulting demand as a function of $w$ is as follows

$$
q(w)=\left\{\begin{array}{clc}
1 & \text { if } & w \leq 1-t \\
(1-w) / t & \text { if } & 1-t \leq w \leq 1
\end{array}\right.
$$


The supplier then maximizes her profit, $Y_{S}$, by setting $w$ and $F$. The supplier's unit production cost is normalized to zero for simplicity. This assumption also makes a saturated market possible in this work. The supplier's profit-maximization problem is thus as follows:

$$
\underset{w, F}{\operatorname{Max}} Y_{S}=w * q(w)+F \text {, subject to } Y_{R} \geq 0
$$

Proposition 1. The equilibrium of the basic model under full information is as follows:

$$
\text { any } w^{*} \in[0,1-t], F^{*}=1-t / 2-w^{*}, p^{*}=1-t / 2, q^{*}=1, Y_{S}^{*}=1-t / 2, Y_{R}^{*}=0 .
$$

In the case of fully integrated supply chain, the channel will choose $p$ to maximize the channel's profit, $\operatorname{Max}_{p} Y=p \cdot q(p)$. It is easy to see that in the integrated supply chain, the optimal price is less than or equal to $1-t / 2$, the optimal demand is 1 , and the optimal channel profit is $1-t / 2$. Proposition 1 shows that two-part tariffs can coordinate the supply chain. But the retailer receives zero profit at equilibrium under two-part tariffs. This effect will be coped with the fact that the retailer has better market knowledge than the supplier in our model. This model of asymmetric information is introduced next.

\subsection{The Model under Asymmetric Information}

In a standard adverse selection model such as the ones in Vives (1999) in economics, and Lutze and Ozer (2008) in operations, the agents typically own some private information unavailable to the principal(s). The principals thus design a menu of contracts, one for each possible type of the agents. Each agent, based on his or her own type, will then choose the contract that benefits him or her the most.

Following the aforementioned conventional adverse selection models, we suppose that the supplier (the principal) does not know customers' unit transportation cost $t$, but the retailer does. The supplier believes that $t$ follows a Bernoulli distribution: a consumer has a low unit transportation cost $(t=$ $t_{l}$ ) with probability $\pi$, and a high unit transportation cost $\left(t=t_{h}\right)$ with probability $1-\pi$, where $t_{l}<t_{h}$. A retailer facing $t_{l}\left(t_{h}\right)$ is called $t_{l}$-type ( $t_{h}$-type) retailer. The supplier can offer a menu of two two-part tariff contracts. These two contracts are: $\left(w_{l}, F_{l}\right)$ and $\left(w_{h}, F_{h}\right)$, where $w_{l}$ and $w_{h}$ are the wholesale prices designated for the retailer when $t=t_{l}$ and $t=t_{h}$, respectively; $F_{l}$ and $F_{h}$ are franchise fees designated for the retailer when $t=t_{l}$ and $t=t_{h}$, respectively. For the retailer, $w_{l}$ and $w_{h}$ are variable costs whereas $F_{l}$ and $F_{h}$ are fixed costs. Similarly, $p_{l}$ and $p_{h}$ are the retail prices set by $t_{l}$-type and $t_{h}$-type retailer, respectively. $q_{l}$ and $q_{h}$ are the demand faced by $t_{l}$-type and $t_{h}$-type retailer, respectively.

To maximize her expected profit, the supplier would like to design a menu of two two-part tariff contracts so that $t_{l}$-type retailer will choose $\left(w_{l}, F_{l}\right)$, and $t_{h}$-type retailer will choose $\left(w_{h}, F_{h}\right)$. Assume 
that the supplier is risk neutral and thus she wants to maximize her expected profit $E\left(Y_{S}\right)$. The supplier's problem is then given by the following constrained optimization problem:

$$
\begin{array}{ll}
\operatorname{Max} & E\left(Y_{S}\right)=\pi\left(w_{l} q_{l}+F_{l}\right)+(1-\pi)\left(w_{h} q_{h}+F_{h}\right) \\
\text { s.t. } & {\left[p_{l}\left(w_{l}\right)-w_{l}\right] \cdot q_{l}\left(w_{l}\right)-F_{l} \geq 0} \\
& {\left[p_{h}\left(w_{h}\right)-w_{h}\right] \cdot q_{h}\left(w_{h}\right)-F_{h} \geq 0} \\
& {\left[p_{l}\left(w_{l}\right)-w_{l}\right] \cdot q_{l}\left(w_{l}\right)-F_{l} \geq\left[p_{l}\left(w_{h}\right)-w_{h}\right] \cdot q_{l}\left(w_{h}\right)-F_{h}} \\
& {\left[p_{h}\left(w_{h}\right)-w_{h}\right] \cdot q_{h}\left(w_{h}\right)-F_{h} \geq\left[p_{h}\left(w_{l}\right)-w_{l}\right] \cdot q_{h}\left(w_{l}\right)-F_{l}}
\end{array}
$$

(IR1) and (IR2) are the individual rationality constraints for a $t_{l}$-type and a $t_{h}$-type retailer, respectively. These constraints ensure that the retailer will obtain non-negative profit. (IC1) and (IC2) are the incentive compatibility constraints for $t_{l}$-type and $t_{h}$-type retailer, respectively. These two constraints ensure that the retailer facing $t_{l}$ will not choose $\left(w_{h}, F_{h}\right)$ and the retailer facing $t_{h}$ will not choose $\left(w_{l}, F_{l}\right)$. The incentive compatibility constraints simply mean that the retailer will only choose the contract designed for his type.

In order to find the optimal solution to the above model, we need the following two lemmas.

Lemma 1. At the optimum, $\left[p_{l}\left(w_{h}\right)-w_{h}\right] \cdot q_{l}\left(w_{h}\right)>\left[p_{h}\left(w_{h}\right)-w_{h}\right] \cdot q_{h}\left(w_{h}\right)$. As a result,

$$
F_{h}=\left[p_{h}\left(w_{h}\right)-w_{h}\right] \cdot q_{h}\left(w_{h}\right) \text {. }
$$

Proof. Proofs of all lemmas and propositions can be found in the Appendix.

Lemma 1 indicates that (IR2) must be binding at optimum. In other words, the supplier will design the menu of contracts so that $t_{h}$-type retailer will receive zero profit.

Lemma 2. At the optimum, (IC1) must be binding. That is,

$$
\left[p_{l}\left(w_{l}\right)-w_{l}\right] \cdot q_{l}\left(w_{l}\right)-F_{l}=\left[p_{l}\left(w_{h}\right)-w_{h}\right] \cdot q_{l}\left(w_{h}\right)-F_{h} .
$$

Lemma 2 shows that at optimum, a $t_{l}$-type retailer will be indifferent between the two contracts, $\left(w_{l}, F_{l}\right)$ and $\left(w_{h}, F_{h}\right)$.

According to Lemmas 1 and 2, once the optimal values of $w_{l}$ and $w_{h}$ are known, it is straightforward to compute the optimal values of $F_{l}$ and $F_{h}$ using Equations (8) and (9). The difficulty in solving this optimization model, even after having been simplified by Lemmas 1 and 2, is that the objective function is piece-wise differentiable. To deal with this difficulty, we consider all the possible scenarios for the two wholesale prices. In principle, there are 25 scenarios. Thus, we identify the optimum for each of the 25 scenarios one by one. The optimum of each scenario is called a local optimum. By comparing all the local optima, we can obtain the global optimal solution(s) to the supplier's optimization 
problem. The 25 possible scenarios of the combinations of the two wholesale prices are summarized in Table 2 below.

Table 2: Possible Scenarios of Optimal Wholesale Prices

\begin{tabular}{|c|c|c|c|c|c|}
\hline & $w_{h}<1-t_{h}$ & $w_{h}=1-t_{h}$ & $1-t_{h}<w_{h}<1-t_{l}$ & $w_{h}=1-t_{l}$ & $1-t_{l}<w_{h}<1$ \\
\hline$w_{l}<1-t_{h}$ & $\begin{array}{c}\mathrm{S} 1 \\
\left(\mathrm{LWS}^{*}\right)\end{array}$ & $\begin{array}{c}\mathrm{S} 2 \\
\left(\mathrm{LWS}^{*}\right)\end{array}$ & $\begin{array}{c}\text { S3 } \\
\text { (infeasible) }\end{array}$ & $\begin{array}{c}\mathrm{S} 4 \\
(\mathrm{FWS} * *)\end{array}$ & $\begin{array}{c}\text { S5 } \\
\left(\mathrm{HWS}^{* * *}\right)\end{array}$ \\
\hline$w_{l}=1-t_{h}$ & $\begin{array}{c}\mathrm{S6} \\
(\mathrm{LWS} *)\end{array}$ & $\begin{array}{c}\mathrm{S} 7 \\
(\mathrm{LWS} *)\end{array}$ & $\begin{array}{c}\text { S8 } \\
\text { (infeasible) }\end{array}$ & $\begin{array}{c}\text { S9 } \\
\left(\mathrm{FWS}^{* *}\right)\end{array}$ & $\begin{array}{c}\mathrm{S} 10 \\
(\mathrm{HWS} * *)\end{array}$ \\
\hline $1-t_{h}<w_{l}<1-t_{l}$ & $\begin{array}{c}\text { S11 } \\
\text { (infeasible) }\end{array}$ & $\begin{array}{c}\mathrm{S} 12 \\
\text { (infeasible) }\end{array}$ & $\begin{array}{c}\text { S13 } \\
\text { (infeasible) } \\
\end{array}$ & $\begin{array}{c}\text { S14 } \\
\left(\text { FWS }^{* *}\right)\end{array}$ & $\begin{array}{c}\mathrm{S} 15 \\
(\mathrm{HWS} * * *) \\
\end{array}$ \\
\hline$w_{l}=1-t_{l}$ & $\begin{array}{c}\text { S16 } \\
\text { (infeasible) }\end{array}$ & $\begin{array}{c}\text { S17 } \\
\text { (infeasible) }\end{array}$ & $\begin{array}{c}\mathrm{S} 18 \\
\text { (infeasible) }\end{array}$ & $\begin{array}{c}\text { S19 } \\
\left(\mathrm{FWS}^{* *}\right)\end{array}$ & $\begin{array}{c}\mathrm{S} 20 \\
(\mathrm{HWS} * * *)\end{array}$ \\
\hline $1-t_{l}<w_{l}<1$ & $\begin{array}{c}\text { S21 } \\
\text { (infeasible) }\end{array}$ & $\begin{array}{c}\text { S22 } \\
\text { (infeasible) }\end{array}$ & $\begin{array}{c}\text { S23 } \\
\text { (infeasible) }\end{array}$ & $\begin{array}{c}\text { S24 } \\
\text { (infeasible) }\end{array}$ & $\begin{array}{c}\mathrm{S} 25 \\
\text { (infeasible) }\end{array}$ \\
\hline
\end{tabular}

*. LWS: low wholesale price strategy in which $w_{h}$ is less than or equal to $1-t_{h}$.

**. FWS: fixed wholesale price strategy in which $w_{h}$ is fixed to be $1-t_{l}$.

***. HWS: high wholesale price strategy in which $w_{h}$ is higher than $1-t_{l}$.

In Table 1, "infeasible" means that the globally optimal solution does not exist in this scenario. As will be formally shown in Lemma 3 below, out of the 25 possible scenarios, there are 13 infeasible scenarios.

Lemma 3. The following 13 scenarios cannot be globally optimal: S3, S8, S11, S12, S13, S16, S17, S18, S21, S22, S23, S23, and S25.

Lemma 3 indicates that the globally optimal solution does not exist in the above 13 scenarios. Consequently, the globally optimal solution for the supplier can only be in the remaining 12 scenarios. We group the remaining scenarios into three groups, according to different two-part tariff contracts offered. Please note that for scenarios in the same group, they have identical optimal retail price, demand, the supplier's profit, and the retailer's profit. Scenarios S1, S2, S6 and S7 are in the same group, which is named as low wholesale price strategy (LWS). Similarly, we name the group including scenarios S4, S9, S14, and S19 fixed wholesale price strategy (FWS), and the group including scenarios S5, S10, S15 and S20 high wholesale price strategy (HWS). In the next section, we will show that each of the three strategies can be globally optimal, depending on the values of the parameters.

\section{Analyses and Results}


In this section, we first present the optimal two-part tariff contract for each scenario of the three strategies (LWS, FWS, and HWS). We then identify the globally optimal two-part tariff contracts at the end of the section.

Proposition 2. The optimal two-part tariff contracts offered by the supplier in the low wholesale price strategy (LWS) are as follows, and the contracts can coordinate the supply chain regardless of the type of the retailer.

\begin{tabular}{|l|l|l|}
\hline $\begin{array}{c}\text { Retailer } \\
\text { type }\end{array}$ & \multicolumn{1}{|c|}{$l$-type } & \multicolumn{1}{c|}{$h$-type } \\
\hline & S1: (any $w$ less than $\left.1-t_{h}, 1-\frac{t_{h}}{2}-w_{l}\right)$ & S1: (any $w$ less than $\left.1-t_{h}, 1-\frac{t_{h}}{2}-w_{h}\right)$ \\
$(w, F)$ & S2: (any $w$ less than $\left.1-t_{h}, 1-\frac{t_{h}}{2}-w_{l}\right)$ & S2: $\left(1-t_{h}, \frac{t_{h}}{2}\right)$ \\
& S6: $\left(1-t_{h}, 1-\frac{t_{h}}{2}\right)$ & S6: (any $w$ less than $\left.1-t_{h}, 1-\frac{t_{h}}{2}-w_{h}\right)$ \\
& S7: $\left(1-t_{h}, \frac{t_{h}}{2}\right)$ & S7: $\left(1-t_{h}, \frac{t_{h}}{2}\right)$
\end{tabular}

The other local optimum results of the low wholesale price strategy, along with the other two strategies, are summarized in Table 3 in the Appendix.

Proposition 2 indicates that, in scenarios S1, S2, and S6, the retailer, regardless of the type, will choose the two-part tariff contract designed for him. In other words, the $t_{l}$-type retailer will not choose the contract designed for the $t_{h}$-type retailer, and vice versa. This finding implies that the supplier is able to differentiate the $t_{l}$-type retailer from the $t_{h}$-type retailer by the retailer's choice of the contract. This outcome is referred to as a separating equilibrium in economics, meaning that different types of retailer will choose different types of contracts. In S7, however, the supplier offers identical contracts to either type of the retailer. This result is referred to as a pooling equilibrium, meaning that the supplier does not differentiate different types of the retailer. The pooling equilibrium is of particular and practical importance and interest. For example, Costco Business Centers simply have one membership fee and all members pay the same prices for the products. This one-size-fits-all two-part tariff is much easier to implement. As we will see in Proposition 5 later on, LWS can be globally optimal. And thus, one-sizefits-all two-part tariff can possibly coordinate the supply chain.

It is worth noting that supply chain coordination can be achieved in a pooling or a separating equilibrium while the wholesale prices $w_{l}$ and $w_{h}$ are relatively low. Thus, we call this contract offering 
low wholesale price strategy (LWS). Proposition 2 suggests that a supply chain coordinator can always induce supply chain coordination by setting a proper price ceiling at $1-t_{h}$.

The most exciting takeaway from Proposition 2 is that the supply chain can be coordinated with two-part tariffs regardless of the type of the retailer. In fact, regardless of the type of the retailer, the entire market will be served. Furthermore, the $t_{l}$-type retailer obtains a positive profit $\frac{t_{h}-t_{l}}{2}$ and the $t_{h}$-type retailer will always receive zero profit because (IR2) is always binding according to Lemma 1. At this moment, it is not clear yet whether the supplier will choose this strategy. In other words, we do not know yet whether LWS can be globally optimal. As will be demonstrated in Proposition 5 later, LWS is indeed globally optimal for the supplier as long as the probability that the retailer is of $t_{l}$-type is sufficiently low.

Proposition 3. The optimal two-part tariff contracts offered by the supplier in the fixed wholesale price strategy (FWS) are as follows, and the supply chain can be coordinated if the retailer is of $t_{l}$-type.

\begin{tabular}{|l|l|c|}
\hline $\begin{array}{c}\text { Retailer } \\
\text { type }\end{array}$ & \multicolumn{1}{|c|}{ l-type } & \multicolumn{1}{|c|}{$h$-type } \\
\hline$(w, F)$ & $\begin{array}{l}\text { S9: }\left(1-t_{h}, t_{h}-t_{l}+\frac{t_{l}^{2}}{2 t_{h}}\right) \\
\left.\text { S14: (Any } w \text { between } 1-t_{h} \text { and } 1-t_{l}, 1-t_{l}-w_{l}+\frac{t_{l}^{2}}{2 t_{h}}\right)\end{array}$ & S4, S9, S14, and S19: \\
& S19: $\left(1-t_{l}, \frac{t_{l}^{2}}{2 t_{h}}\right)$ & $\left(1-t_{l}, \frac{t_{l}^{2}}{2 t_{h}}\right)$ \\
\end{tabular}

According to Proposition 3, on one hand, the locally optimal two-part tariffs offered to the $t_{h}$-type retailer are the same in the four scenarios. The two-part tariffs offered to the $t_{l}$-type retailer, on the other hand, are different. The locally optimal contracts offered in S4, S9 and S14 are separating equilibria because different types of retailer will choose different contracts. The locally optimal contracts offered in S19, however, consist of a pooling equilibrium because the same contracts are offered to different types of retailer. Noting that the optimal wholesale prices for $t_{h}$-type is always $1-t_{l}$, we call these contracts high wholesale price strategies (FWS).

The most important finding in Proposition 3 is that the two-part tariffs can coordinate the supply chain and the market is fully served if the retailer is of the $t_{l}$-type. In addition, the supplier is better off if the retailer is of the $t_{l}$-type, because her profit is always higher than otherwise. Moreover, it is easy to verify that if the retailer is more likely to be of the $t_{l}$-type, then it is better for the supplier to choose FWS than LWS; if the retailer is more likely to be of the $t_{h}$-type, then it is better for the supplier to choose 
LWS than FWS. However, unlike in Proposition 2, the market will not be fully served if the retailer is of the $t_{h}$-type. It is not surprising to see that the $t_{h}$-type retailer receives zero profit.

We will show later on that FWS is globally optimal for the supplier when the probability that the retailer is of the $t_{l}$-type is sufficiently high.

Proposition 4. The optimal two-part tariff contracts offered by the supplier in the high wholesale price strategy (HWS) are as follows, and the supply chain can be coordinated if the retailer is of $t_{l}$-type.

\begin{tabular}{|c|c|c|}
\hline $\begin{array}{c}\text { Retailer } \\
\text { type }\end{array}$ & $l$-type & $h$-type \\
\hline$(w, F)$ & $\begin{array}{l}\text { S5: }\left(\text { Any } w<1-t_{h}, 1-\frac{t_{l}}{2}-w_{l}-\right. \\
\left.\quad \frac{\left(t_{h}-t_{l}\right)\left(1-w_{h}\right)^{2}}{2 t_{h} t_{l}}\right) \\
\text { S10: }\left(1-t_{h}, \frac{3 t_{h} t_{l}-t_{h}{ }^{2}-t_{l}^{2}}{2 t_{l}}\right) \\
\text { S15: (Any } w \in\left(1-t_{h}, 1-t_{l}\right), 1-\frac{t_{l}}{2}- \\
\left.\quad w_{l}-\frac{\left(t_{h}-t_{l}\right)\left(1-w_{h}\right)^{2}}{2 t_{h} t_{l}}\right) \\
\text { S20: }\left(1-t_{l}, \frac{\left(t_{h}-t_{l}\right)^{2}}{2 t_{h}}\right)\end{array}$ & $\begin{array}{l}\text { S5, S10, S15, and S20: } \\
\left(\frac{\pi\left(t_{h}-t_{l}\right)}{\pi t_{h}+(1-2 \pi) t_{l}}, \frac{(\pi-1)^{2} t_{l}^{2}}{2 t_{h}\left(\pi t_{h}+(1-2 \pi) t_{l}\right)^{2}}\right)\end{array}$ \\
\hline
\end{tabular}

Proposition 4 signifies that the locally optimal two-part tariffs offered to the $t_{h}$-type retailer are the same in any of the four scenarios. At the local optimum, the wholesale price offered to the $t_{l}$-type must be less than or equal to $1-t_{l}$. Unlike in Propositions 2 and 3, none of the four optimal two-part tariffs consist of a pooling equilibrium in that different types of retailer will always select a different contract.

Once again, the channel will be coordinated with two-part tariffs and the entire market will be served if the retailer is of the $t_{l}$-type. Nevertheless, if the retailer is of the $t_{h}$-type, then the market will only be partially served and the retailer will receive zero profit. Similar to Proposition 3, the supplier is better off if the retailer is of $t_{l}$-type. The high wholesale price strategy will be shown to be globally optimal for the supplier if the probability that the retailer is of the $t_{l}$-type is not too high or too low.

Proposition 5. The supplier's globally optimal two-part tariff contracts are as follows:

if $0<\pi<\pi_{1}$, then LWS is globally optimal,

if $\pi_{1}<\pi<\pi_{2}$, then HWS is globally optimal, and

if $\pi_{2}<\pi<1$, then FWS is globally optimal.

The values of $\pi_{1}$ and $\pi_{2}$ are: 


$$
\pi_{1}=\frac{-B_{1}+\sqrt{B_{1}^{2}-4 A C_{1}}}{2 A} \text { and } \pi_{2}=\frac{-B_{2}+\sqrt{B_{2}^{2}-4 A C_{2}}}{2 A},
$$

where

$$
\begin{aligned}
& A=\left(2-t_{l}\right)\left(t_{h}-t_{l}\right)^{2}+t_{l}\left(1-t_{l}\right)^{2}>0, \\
& B_{1}=-\left[t_{h}\left(t_{h}-t_{l}\right)\left(2-t_{h}-t_{l}\right)+2 t_{l}\left(1-t_{h}\right)^{2}\right]<0, \\
& C_{1}=t_{l}\left(1-t_{h}\right)^{2}>0, \\
& B_{2}=t_{h} t_{l}\left(2-t_{l}\right)-2 t_{l}-\left(t_{h}-2 t_{l}\right)\left(2 t_{h}\left(1-t_{l}\right)+t_{l}^{2}\right)<0, \text { and } \\
& C_{2}=t_{l}\left(1-t_{l}\right)\left(1-2 t_{h}+t_{l}\right) .
\end{aligned}
$$

If the supplier's subjective probability that $t=t_{l}$ is lower than the threshold value of $\pi_{1}$, then LWS generates the highest expected profit for the supplier. If the supplier's subjective probability that $t=t_{l}$ is higher than the threshold value of $\pi_{2}$, then FWS generates the highest expected profit for the supplier. In the end, if the supplier's subjective probability that $t=t_{l}$ is between $\pi_{1}$ and $\pi_{2}$, then HWS generates the highest expected profit for the supplier. Proposition 5 is straightforward. First, if the probability that the retailer is of $t_{l}$-type is sufficiently low (less than $\pi_{1}$ ), then consumers are likely to make the purchase when retail price is sufficiently low. Therefore, LWS is the supplier's globally optimal strategy to induce low retail price. Second, if the probability that the retailer is of $t_{l}$-type is sufficiently high (greater than $\pi_{2}$ ), then the demand can still be relatively high when the retail price is high. As a result, FWS is the globally optimal strategy of the supplier to better extract profit from the retailer and consumers. Third, if the probability that the retailer is of $t_{l}$-type is between $\pi_{1}$ and $\pi_{2}$, then HWS is the globally optimal strategy.

Proposition 5, together with Propositions 2, 3, and 4, confirms that the channel coordination will always be achieved if the retailer is of $t_{l}$-type. In this case, the entire market is served and the retailer receives positive profit. If the retailer is of $t_{h}$-type, however, the channel will be coordinated and the market will be fully served in LWS, but not in FWS and HWS. The $t_{h}$-type always receives zero profit.

It is important to note that both the supplier and the retailer are better off if the transportation cost $t$ is low $\left(t=t_{l}\right)$. However, if the supplier knows the exact transportation cost, then the supplier will take advantage of the situation and leave the retailer zero profit, even though the channel will be coordinated (Proposition 1). Consider a more general model in which the transportation cost $t$ can take on $n$ possible values ranging from $t_{l}$ to $t_{h}$ with positive probabilities. It is easy to see that Lemmas 1 and 2 can be generalized to this general model. Therefore, only retailer facing $t_{h}$ will receive zero profit. In the other $n-1$ cases, retailer obtains positive profit at equilibrium. 


\section{Summary}

Built upon a linear city model of market demand, this paper introduces two new elements into the study of supply chain coordination with two-part tariffs: (1) a near-saturated market, (2) information asymmetry in which the retailer has better market knowledge than the supplier. To be more specific, the retailer knows the exact transportation cost of customers whereas the supplier does not.

This paper has added three important and interesting results to the existing supply chain coordination literature. First, it shows that a two-echelon supply chain can be coordinated with two-part tariffs under asymmetric information. Much scholarly attention has been paid to other forms of supply contracts, such as buy-back contracts, quantity flexibility contracts, revenue sharing contracts, and quantity discount contracts. Two-part tariffs, together with arguably most popular supply contractwholesale price contract, receive much less attention. One possible reason is that contracts like buy-back can coordinate supply chains in theory while two-part tariffs and wholesale price contracts cannot in general. The first major contribution of this paper fills such a gap by providing a theoretical explanation to the prevalence of two-part tariffs: two-part tariffs are capable of coordinating supply chains.

In the existing literature, when two-part tariffs do achieve channel coordination under full information, the retailer receives zero profit. This result is apparently at odds with reality, and is probably another reason why two-part tariffs receive less scholarly attention. The existing explanation to this unpleasant property is the introduction of external opportunity for the retailer. Thus, the second major contribution of this paper is to have shown that the retailer can receive positive profit in a supply chain coordinated with two-part tariffs under information asymmetry. This is an endogenous equilibrium result.

Lastly, from a practical standpoint, it is rare that a supplier designs a menu of two-part tariffs. Our results have shown that the supplier can design a one-size-fits-all two-part tariff to maximize her own expect profit while coordinating the supply chain. It is true in both the low-wholesale-price strategy (LWS) and the fixed-wholesale-price strategy (FWS).

This paper opens a door to many possible opportunities for future research. First, in this work, the supplier is the Stackelberg leader while the retailer is the follower. In some industries, however, retailers are the more powerful players than the suppliers. It will be interesting to investigate whether two-part tariffs, especially designed by the retailer, can coordinate the channel. Second, the information asymmetry considered in this paper is the retailer's better market knowledge, condensed into one parameter -consumers' unit transportation cost. It is worthwhile looking into other forms of information asymmetry, such as the retailer's own cost. Third, this paper studies a near-saturated market in which two-part tariffs can coordinate the supply chain. However, it is still unclear whether two-part tariffs can coordinate the 
supply chain in an unsaturated market. Fourth, this paper adopts an adverse selection model from Economics. Is it possible to employ moral hazard model in a similar fashion? We view this direction as a potential path for continued research.

\section{References}

Agrawal, V., Seshadri, S., 2000. Risk intermediation in supply chains. IIE Transactions, 32(9), 819-831.

Babich, V., Li, H., Ritchken, P., Wang, Y., 2012. Contracting with asymmetric demand information in supply chains. European Journal of Operational Research, 217(2), 333-341.

Cachon, G., 2003. Supply chain coordination with contracts. In: Handbooks in Operations Research and Management Science: Supply Chain Management. Elsevier Science Publishers, Holland.

Cachon, G., Lariviere, M., 2005. Supply chain coordination with revenue sharing contracts: strength and limitations. Management Science, 51(1), 30-44.

Çakanyıldırım, M., Feng, Q., Gan, X., Sethi, S. P., 2012. Contracting and coordination under asymmetric production cost information. Production and Operations Management, 21(2), 345-360.

Chan, H. K., \& Chan, F. T., 2010. A review of coordination studies in the context of supply chain dynamics. International Journal of Production Research, 48(10), 2793-2819.

Chen, J., Zhang, H., \& Sun, Y., 2012. Implementing coordination contracts in a manufacturer Stackelberg dual-channel supply chain. Omega, 40(5), 571-583.

Chen, K., Yang, L., 2014. Random yield and coordination mechanisms of a supply chain with emergency backup sourcing. International Journal of Production Research, 52(16), 4747-4767.

Corbett, C.J., Zhou, D., Tang, C.S., 2004. Designing supply contracts: contract type and information asymmetry. Management Science, 50(4), 550-559.

Ha, A. Y., 2001. Supplier-buyer contracting: Asymmetric cost information and cutoff level policy for buyer participation. Naval Research Logistics, 48(1), 41-64.

Hematyar, S., Chaharsooghi, K., Malakafali, P., 2014. Supply chain coordination with consumer returns using a sales rebate contract and VMI partnership. Proceedings of the 2014 Industrial and Systems Engineering Research Conference.

Huang, G.Q., Lau, J.S., Mak, K.L., 2003. The impacts of sharing production information on supply chain dynamics: a review of the literature. International Journal of Production Research, 41(7), 1483-1517. 
Lutze, H., Özer, Ö., 2008. Promised lead-time contracts under asymmetric information. Operations Research, 56(4), 898-915.

Moorthy, K. S., 1987. Comment-managing channel profits: Comment. Marketing Science, 6(4), 375-379.

Pasternack, B., 1985. Optimal pricing and returns policies for perishable commodities. Marketing Science, 4(2), 166-176.

Reisinger, M., 2014. Two-Part tariff competition between two-sided platforms, European Economic Review, 68, 168-180.

Sabbaghi, N., Sheffi, Y., Tsitsiklis, J.N., 2007. Coordinating a constrained channel with linear wholesale price contracts. Massachusetts Institute of Technology, LIDS Technical Report, \#2749.

San Martin, M., Saracho, A. I., 2015. Optimal two-part tariff licensing mechanisms. The Manchester School, 83(3), 288-306.

Swaminathan, J. M., Tayur, S. R., 2003. Models for supply chains in e-business. Management Science, 49(10), 1387-1406.

Tsay A., 1999. The quantity flexibility contract and supplier-customer incentives. Management Science, 45(10), 1339-1358.

Vettas, N., 2011. Two-part tariffs. The New Palgrave Dictionary of Economics Online. Palgrave Mcmillan. <http://www.dictionaryofeconomics.com/article?id=pde2011_T000188>

Vives, X., 1999. Oligopoly Pricing: Old Ideas and New Tools. MIT Press.

Wang, J., Lau, A. H., Lau, H., 2012. Practical and effective contracts for the dominant retailer of a newsvendor product with price-sensitive demand. International Journal of Production Economics, 138(1), 46-54.

Weng, Z., 1995. Channel coordination and quantity discounts. Management Science, 41(9), 1509-1522.

Yang, S., Munson, C. L., Chen, B., 2010. Using MSRP to enhance the ability of rebates to control distribution channels. European Journal of Operational Research, 205(1), 127-135.

Zhang, F., 2010. Procurement mechanism design in a two-echelon inventory system with price-sensitive demand. Manufacturing \& Service Operations Management, 12(4), 608-626.

Zusman, P., Etgar, M., 1981. The marketing channel as an equilibrium set of contracts. Management Science, 27(3), 284-302. 


\section{Appendix:}

Table 3: Local Optimum of LWS, FWS, and HWS

\begin{tabular}{|c|c|c|c|c|c|c|}
\hline Strategies & $\begin{array}{c}\text { Retailer } \\
\text { Type }\end{array}$ & $\begin{array}{c}\text { Retail } \\
\text { Price }\end{array}$ & Demand & $\begin{array}{c}\text { Supplier's } \\
\text { Profit }\end{array}$ & $\begin{array}{c}\text { Retailer's } \\
\text { Profit }\end{array}$ & $\begin{array}{c}\text { Supply } \\
\text { Chain's Profit }\end{array}$ \\
\hline \multirow{3}{*}{ LWS } & l-type & $1-\frac{t_{l}}{2}$ & 1 & $1-\frac{t_{h}}{2}$ & $\frac{t_{h}-t_{l}}{2}$ & $1-\frac{t_{l}}{2}$ \\
\cline { 2 - 7 } & $h$-type & $1-\frac{t_{h}}{2}$ & 1 & $1-\frac{t_{h}}{2}$ & 0 & $1-\frac{t_{h}}{2}$ \\
\hline \multirow{2}{*}{ FWS } & l-type & $1-\frac{t_{l}}{2}$ & 1 & $1-t_{l}+\frac{t_{l}^{2}}{2 t_{h}}$ & $\frac{t_{h}}{2}-\frac{t_{l}^{2}}{2 t_{h}}$ & $1-\frac{t_{l}}{2}$ \\
\cline { 2 - 7 } & $h$-type & $1-\frac{t_{l}}{2}$ & $\frac{t_{l}}{t_{h}}$ & $\frac{\left(1-t_{l}\right) t_{l}}{t_{h}}+\frac{t_{l}^{2}}{2 t_{h}}$ & 0 & $\frac{\left(1-t_{l}\right) t_{l}}{t_{h}}+\frac{t_{l}^{2}}{2 t_{h}}$ \\
\hline \multirow{3}{*}{ HWS } & l-type & $1-\frac{t_{l}}{2}$ & 1 & $1-\frac{t_{l}}{2}-\frac{\left(t_{h}-t_{l}\right)\left(1-w_{h}\right)^{2}}{2 t_{h} t_{l}}$ & $\frac{\left(t_{h}-t_{l}\right)\left(1-w_{h}\right)^{2}}{2 t_{h} t_{l}}$ & $1-\frac{t_{l}}{2}$ \\
\cline { 2 - 7 } & $h$-type & $\frac{1+w_{h}}{2}$ & $\frac{1-w_{h}}{t_{h}}$ & $\frac{1-w_{h}^{2}}{2 t_{h}}$ & 0 & $\frac{1-w_{h}^{2}}{2 t_{h}}$ \\
\hline
\end{tabular}

Note: LWS is low wholesale price strategy, FWS is fixed wholesale price strategy, and HWS is high wholesale price strategy.

\section{Proof of Results}

\section{Proof of Proposition 1}

It is obvious that when $w \leq 1-t$, the optimal $w$ is $1-t$. The resulting values of $F, p, q, Y_{S}$, and $Y_{R}$ will be $t / 2,1-t / 2,1,1-t / 2$, and 0 , respectively.

When $w \geq 1-t$, the first-order condition yields that the optimal $\mathrm{w}$ is $1 / 2$. The resulting values of $F, p, q$, $Y_{S}$, and $Y_{R}$ will be $1 /(8 t), 3 / 4,1 /(2 t), 3 /(8 t)$, and 0 , respectively. But this is true only if $w \geq 1-t$, or equivalently, $t \geq 1 / 2$. When $t \geq 1 / 2$, it can be easily shown that $1-t / 2$ is greater than $3 /(8 t)$. Therefore, $\mathrm{w}^{*}=1-t$ will be the only optimal wholesale price.

\section{Proof of Lemma 1}

Consider three possible scenarios of $w_{h}$, respectively. These are: (a) $w_{h} \leq 1-t_{h}<1-t_{l}$; (b) $1-t_{h}<$ $w_{h}<1-t_{l}$; and (c) $1-t_{h}<1-t_{l} \leq w_{h}<1$.

In case (a), $p_{h}=1-t_{h} / 2, p_{l}=1-t_{l} / 2$, and $q_{h}=q_{l}=1$. This is directly from equations (2) and (3). So,

$$
\begin{aligned}
& {\left[p_{l}\left(w_{h}\right)-w_{h}\right] \cdot q_{l}\left(w_{h}\right)=1-\frac{t_{l}}{2}-w_{h}} \\
& {\left[p_{h}\left(w_{h}\right)-w_{h}\right] \cdot q_{h}\left(w_{h}\right)=1-\frac{t_{h}}{2}-w_{h} .}
\end{aligned}
$$

It is obvious that $1-\frac{t_{l}}{2}>1-\frac{t_{h}}{2}$. Thus, $\left[p_{l}\left(w_{h}\right)-w_{h}\right] \cdot q_{l}\left(w_{h}\right)>\left[p_{h}\left(w_{h}\right)-w_{h}\right] \cdot q_{h}\left(w_{h}\right)$.

$$
\text { In case (b), } p_{h}=\left(1+w_{h}\right) / 2, p_{l}=1-t_{l} / 2, q_{h}=\left(1-w_{h}\right) / t_{h} \text {, and } q_{l}=1 \text {. Let } x=1-w_{h} \text {. }
$$

Since $1-t_{h}<w_{h}<1-t_{l}$, it must be true that $t_{l}<x<t_{h}$. Therefore,

$$
\left[p_{l}\left(w_{h}\right)-w_{h}\right] \cdot q_{l}\left(w_{h}\right)=1-\frac{t_{l}}{2}-w_{h}=x-\frac{t_{l}}{2}
$$




$$
\left[p_{h}\left(w_{h}\right)-w_{h}\right] \cdot q_{h}\left(w_{h}\right)=\frac{\left(1-w_{h}\right)^{2}}{2 t_{h}}=\frac{x^{2}}{2 t_{h}} .
$$

Let $f(x)=x-\frac{t_{l}}{2}-\frac{x^{2}}{2 t_{h}}$ for $x \in\left[t_{l}, t_{h}\right]$. Obviously, $f^{\prime \prime}(x)=\frac{1}{t_{h}}>0$ and thus, $f(x)$ reaches maximum when $f^{\prime}(x)=0$ or equivalently, when $x=t_{h}$. So, $f(x)$ increases in $x$ for $x \in\left[t_{l}, t_{h}\right]$. Thus, $f(x)$ reaches its minimum at $x=t_{l} . f\left(x=t_{l}\right)=\frac{t_{l}\left(t_{h}-t_{l}\right)}{2 t_{h}}>0$. Therefore, $\left[p_{l}\left(w_{h}\right)-w_{h}\right] \cdot q_{l}\left(w_{h}\right)>\left[p_{h}\left(w_{h}\right)-w_{h}\right]$. $q_{h}\left(w_{h}\right)$ is also true in case (b).

$$
\begin{aligned}
& \text { In case }(\mathrm{c}), p_{h}=p_{l}=\left(1+w_{h}\right) / 2, q_{h}=\left(1-w_{h}\right) / t_{h}, \text { and } q_{l}=\left(1-w_{h}\right) / t_{l} . \\
& {\left[p_{l}\left(w_{h}\right)-w_{h}\right] \cdot q_{l}\left(w_{h}\right)=\frac{\left(1-w_{h}\right)^{2}}{2 t_{l}}} \\
& {\left[p_{h}\left(w_{h}\right)-w_{h}\right] \cdot q_{h}\left(w_{h}\right)=\frac{\left(1-w_{h}\right)^{2}}{2 t_{h}} .}
\end{aligned}
$$

It is obvious that $\left[p_{l}\left(w_{h}\right)-w_{h}\right] \cdot q_{l}\left(w_{h}\right)>\left[p_{h}\left(w_{h}\right)-w_{h}\right] \cdot q_{h}\left(w_{h}\right)$. According to constraint (IC1), the following must be true:

$$
\left[p_{l}\left(w_{l}\right)-w_{l}\right] \cdot q_{l}\left(w_{l}\right)-F_{l} \geq\left[p_{l}\left(w_{h}\right)-w_{h}\right] \cdot q_{l}\left(w_{h}\right)-F_{h}>\left[p_{h}\left(w_{h}\right)-w_{h}\right] \cdot q_{h}\left(w_{h}\right)-F_{h} .
$$

If $\left[p_{h}\left(w_{h}\right)-w_{h}\right] \cdot q_{h}\left(w_{h}\right)-F_{h}$ is not equal to zero, then the supplier can increase $F_{l}$ and $F_{h}$ by the same amount simultaneously without violating any constraint. Thus, at the optimum, it must be true that $\left[p_{h}\left(w_{h}\right)-w_{h}\right] \cdot q_{h}\left(w_{h}\right)-F_{h}=0$. This completes the proof.

\section{Proof of Lemma 2}

Assume that Lemma 2 is not true. That is, $\left[p_{l}\left(w_{l}\right)-w_{l}\right] \cdot q_{l}\left(w_{l}\right)-F_{l}>\left[p_{l}\left(w_{h}\right)-w_{h}\right] \cdot q_{l}\left(w_{h}\right)-F_{h}$.

Based on Lemma 1 and the assumption, the following must be true:

$$
\left[p_{l}\left(w_{l}\right)-w_{l}\right] \cdot q_{l}\left(w_{l}\right)-F_{l}>\left[p_{l}\left(w_{h}\right)-w_{h}\right] \cdot q_{l}\left(w_{h}\right)-F_{h}>\left[p_{h}\left(w_{h}\right)-w_{h}\right] \cdot q_{h}\left(w_{h}\right)-F_{h}=0 .
$$

Thus, the supplier can benefit from increasing $F_{l}$ by a small amount without violating any constraint. Consequently, at optimum, it must be true that $\left[p_{l}\left(w_{l}\right)-w_{l}\right] \cdot q_{l}\left(w_{l}\right)-F_{l}=\left[p_{l}\left(w_{h}\right)-w_{h}\right] \cdot q_{l}\left(w_{h}\right)-$ $F_{h}$.

\section{Proof of Lemma 3.}

S3: $w_{l}<1-t_{h}$ and $1-t_{h}<w_{h}<1-t_{l}$ is infeasible at optimum.

According to Equations (3) and (4),

$$
\begin{aligned}
& p_{l}\left(w_{l}\right)=p_{l}\left(w_{h}\right)=1-\frac{t_{l}}{2}, q_{l}\left(w_{l}\right)=q_{l}\left(w_{h}\right)=1, \\
& p_{h}\left(w_{h}\right)=\frac{1+w_{h}}{2}, q_{h}\left(w_{h}\right)=\frac{1-w_{h}}{t_{h}}, p_{h}\left(w_{l}\right)=1-\frac{t_{h}}{2}, q_{h}\left(w_{l}\right)=1 .
\end{aligned}
$$

According to Lemmas 1 and 2,

$$
F_{h}=\frac{\left(1-w_{h}\right)^{2}}{2 t_{h}} \text { and } F_{l}=w_{h}-w_{l}+F_{h} \text {. }
$$

It can be verified that IC2 is also satisfied. The expected profit of the supplier is

$$
\begin{aligned}
& E\left(Y_{S}\right)=\pi\left(w_{l}+w_{h}-w_{l}+\frac{\left(1-w_{h}\right)^{2}}{2 t_{h}}\right)+(1-\pi)\left(w_{h} \frac{1-w_{h}}{t_{h}}+\frac{\left(1-w_{h}\right)^{2}}{2 t_{h}}\right) \\
& =\pi w_{h}+\frac{(1-\pi) w_{h}\left(1-w_{h}\right)}{t_{h}}+\frac{\left(1-w_{h}\right)^{2}}{2 t_{h}}
\end{aligned}
$$

The first-order condition for maximizing $E\left(Y_{S}\right)$ yields

$$
w_{h}=\frac{\pi\left(1-t_{h}\right)}{2 \pi-1} .
$$

In order for $w_{h}=\frac{\pi\left(1-t_{h}\right)}{2 \pi-1}$ to maximize $E\left(Y_{S}\right)$, it must be true that 


$$
\frac{d^{2} E\left(Y_{S}\right)}{d w_{h}^{2}}=\frac{2 \pi-1}{t_{h}}<0 \text { or } \pi<\frac{1}{2} .
$$

But if $\pi<\frac{1}{2}$, then $w_{h}=\frac{\pi\left(1-t_{h}\right)}{2 \pi-1}<0$. The conflict indicates that there is no such optimal solution that $w_{l}<1-t_{h}$ and $1-t_{h}<w_{h}<1-t_{l}$.

S8: $w_{l}=1-t_{h}$ and $1-t_{h}<w_{h}<1-t_{l}$ is infeasible at optimum.

According to Equations (3) and (4),

$$
\begin{aligned}
& p_{l}\left(w_{l}\right)=p_{l}\left(w_{h}\right)=1-\frac{t_{l}}{2}, q_{l}\left(w_{l}\right)=q_{l}\left(w_{h}\right)=1, \\
& p_{h}\left(w_{h}\right)=\frac{1+w_{h}}{2}, q_{h}\left(w_{h}\right)=\frac{1-w_{h}}{t_{h}}, p_{h}\left(w_{l}\right)=1-\frac{t_{h}}{2}, q_{h}\left(w_{l}\right)=1 .
\end{aligned}
$$

According to Lemmas 1 and 2,

$$
F_{h}=\frac{\left(1-w_{h}\right)^{2}}{2 t_{h}} \text { and } F_{l}=w_{h}-w_{l}+F_{h} .
$$

It can be verified that IC2 is also satisfied. The expected profit of the supplier is thus

$$
\begin{aligned}
& E\left(Y_{S}\right)=\pi\left(w_{l}+F_{l}\right)+(1-\pi)\left(w_{h} \frac{1-w_{h}}{t_{h}}+F_{h}\right) \\
& =\pi\left(w_{h}+\frac{\left(1-w_{h}\right)^{2}}{2 t_{h}}\right)+(1-\pi)\left(w_{h} \frac{1-w_{h}}{t_{h}}+\frac{\left(1-w_{h}\right)^{2}}{2 t_{h}}\right) \\
& =\pi w_{h}+\frac{(1-\pi) w_{h}\left(1-w_{h}\right)}{t_{h}}+\frac{\left(1-w_{h}\right)^{2}}{2 t_{h}}
\end{aligned}
$$

The first-order condition for maximizing $E\left(Y_{S}\right)$ yields

$$
w_{h}=\frac{\pi\left(1-t_{h}\right)}{3 \pi-2} .
$$

In order for $w_{h}=\frac{\pi\left(1-t_{h}\right)}{3 \pi-2}$ to maximize $E\left(Y_{S}\right)$, it must be true that

$$
\frac{d^{2} E\left(Y_{S}\right)}{d w_{h}^{2}}=\frac{3 \pi-2}{t_{h}}<0 \text { or } \pi<\frac{2}{3} .
$$

But if $\pi<\frac{2}{3}$, then $w_{h}=\frac{\pi\left(1-t_{h}\right)}{3 \pi-2}<0$. The conflict indicates that there is no such optimal solution that $w_{l}=1-t_{h}$ and $1-t_{h}<w_{h}<1-t_{l}$.

$\mathrm{S} 11, \mathrm{~S} 12$, and $\mathrm{S} 13$ are similar. Here we prove that the optimal solution cannot be in S11.

S11: $1-t_{h}<w_{l}<1-t_{l}$ and $w_{h}<1-t_{h}$ is infeasible at optimum.

According to Equations (3) and (4),

$$
\begin{aligned}
& p_{l}\left(w_{l}\right)=p_{l}\left(w_{h}\right)=1-\frac{t_{l}}{2}, q_{l}\left(w_{l}\right)=q_{l}\left(w_{h}\right)=1, \\
& p_{h}\left(w_{h}\right)=1-\frac{t_{h}}{2}, q_{h}\left(w_{h}\right)=1, p_{h}\left(w_{l}\right)=\frac{1+w_{l}}{2}, q_{h}\left(w_{l}\right)=\frac{1-w_{l}}{t_{h}} .
\end{aligned}
$$

According to Lemmas 1 and 2,

$$
\begin{aligned}
& F_{h}=1-\frac{t_{h}}{2}-w_{h} \text { and } F_{l}=1-\frac{t_{h}}{2}-w_{l} . \\
& E\left(Y_{S}\right)=\pi\left(w_{l}+F_{l}\right)+(1-\pi)\left(w_{h}+F_{h}\right)=1-\frac{t_{h}}{2} .
\end{aligned}
$$

Constraint IC2 requires that $F_{l} \geq\left[p_{h}\left(w_{l}\right)-w_{l}\right] \cdot q_{h}\left(w_{l}\right)$, which is equivalent to

$$
1-\frac{t_{h}}{2}-w_{l} \geq \frac{\left(1-w_{l}\right)^{2}}{2 t_{h}} \Leftrightarrow\left(1-w_{l}\right)^{2}-2 t_{h}\left(1-w_{l}\right)+t_{h}^{2}=\left(1-w_{l}-t_{h}\right)^{2} \leq 0 .
$$

The above inequality is obviously false. Thus, the optimal wholesale prices cannot be in $\mathrm{S} 11$.

S16, S17, and S18 are similar. Here we prove that the optimal solution cannot be in S16.

S16: $w_{l}=1-t_{l}$ and $w_{h}<1-t_{h}$ is infeasible at optimum. 
According to Equations (3) and (4),

$$
\begin{aligned}
& p_{l}\left(w_{l}\right)=p_{l}\left(w_{h}\right)=1-\frac{t_{l}}{2}, q_{l}\left(w_{l}\right)=q_{l}\left(w_{h}\right)=1, \\
& p_{h}\left(w_{h}\right)=1-\frac{t_{h}}{2}, q_{h}\left(w_{h}\right)=1, p_{h}\left(w_{l}\right)=\frac{1+w_{l}}{2}, q_{h}\left(w_{l}\right)=\frac{1-w_{l}}{t_{h}} .
\end{aligned}
$$

According to Lemmas 1 and 2,

$$
\begin{aligned}
& F_{h}=1-\frac{t_{h}}{2}-w_{h} \text { and } F_{l}=1-\frac{t_{h}}{2}-w_{l}=t_{l}-\frac{t_{h}}{2} . \\
& E\left(Y_{S}\right)=\pi\left(w_{l}+F_{l}\right)+(1-\pi)\left(w_{h}+F_{h}\right)=1-\frac{t_{h}}{2} .
\end{aligned}
$$

Constraint IC2 requires that $F_{l} \geq\left[p_{h}\left(w_{l}\right)-w_{l}\right] \cdot q_{h}\left(w_{l}\right)$, which is equivalent to

$$
t_{l}-\frac{t_{h}}{2} \geq \frac{\left(1-w_{l}\right)^{2}}{2 t_{h}}=\frac{t_{l}^{2}}{2 t_{h}} \Leftrightarrow\left(t_{h}-t_{l}\right)^{2} \leq 0 .
$$

The above inequality is obviously false. Thus, the optimal wholesale prices cannot be in S16.

S21-S25 are similar. Here we prove that the optimal solution cannot be in S21.

S21: $1-t_{l}<w_{l}<1$ and $w_{h}<1-t_{h}$ is infeasible at optimum.

According to Equations (3) and (4),

$$
\begin{aligned}
& p_{l}\left(w_{l}\right)=\frac{1+w_{l}}{2}, q_{l}\left(w_{l}\right)=\frac{1-w_{l}}{t_{l}}, p_{l}\left(w_{h}\right)=1-\frac{t_{l}}{2}, q_{l}\left(w_{h}\right)=1, \\
& p_{h}\left(w_{h}\right)=1-\frac{t_{h}}{2}, q_{h}\left(w_{h}\right)=1, p_{h}\left(w_{l}\right)=\frac{1+w_{l}}{2}, q_{h}\left(w_{l}\right)=\frac{1-w_{l}}{2} .
\end{aligned}
$$

According to Lemmas 1 and 2,

$$
\begin{aligned}
& F_{h}=1-\frac{t_{h}}{2}-w_{h} \text { and } F_{l}=\frac{\left(1-w_{l}\right)^{2}}{2 t_{l}}-\frac{t_{h}-t_{l}}{2} . \\
& E\left(Y_{S}\right)=\pi\left(w_{l}+F_{l}\right)+(1-\pi)\left(w_{h}+F_{h}\right)=\frac{\pi w_{l}\left(1-w_{l}\right)}{t_{l}}+\frac{\pi\left(1-w_{l}\right)^{2}}{2 t_{l}}-\frac{\pi\left(t_{h}-t_{l}\right)}{2}+(1-\pi)\left(1-\frac{t_{h}}{2}\right) . \\
& \frac{d E\left(Y_{S}\right)}{d w_{l}}=\frac{-\pi w_{l}}{t_{l}}<0 .
\end{aligned}
$$

Therefore, there exists no optimal solution within S21.

\section{Proof of Proposition 2.}

Here, we prove the results under S1. The results under S2, S6, and S7 can be shown in a similar fashion. Note that in $\mathrm{S} 1, w_{l}<1-t_{h}$ and $w_{h}<1-t_{h}$. According to Equations (3) and (4),

$$
\begin{aligned}
& p_{l}\left(w_{l}\right)=p_{l}\left(w_{h}\right)=1-\frac{t_{l}}{2}, q_{l}\left(w_{l}\right)=q_{l}\left(w_{h}\right)=1, \\
& p_{h}\left(w_{h}\right)=p_{h}\left(w_{l}\right)=1-\frac{t_{h}}{2}, q_{h}\left(w_{h}\right)=q_{h}\left(w_{l}\right)=1 .
\end{aligned}
$$

According to Lemmas 1 and 2

$$
F_{h}=1-\frac{t_{h}}{2}-w_{h} \text { and } F_{l}=1-\frac{t_{h}}{2}-w_{l} .
$$

It can be easily shown that IC2 is also active. The expected profit function of the supplier is

$$
E\left(Y_{S}\right)=1-\frac{t_{h}}{2}
$$

which is a constant. Therefore, $w_{l}$ and $w_{h}$ can assume any value less than $1-t_{h}$. The resulting profit of the $t_{l}$-type retailer is $Y_{R}=\frac{t_{h}-t_{l}}{2}$.

\section{Proof of Proposition 3.}

Here, we prove the results under S4. The results under S9, S14, and S19 can be shown in a similar fashion. Note that in $\mathrm{S} 4, w_{l}<1-t_{h}$ and $w_{h}=1-t_{l}$. According to Equations (3) and (4), 


$$
\begin{aligned}
& p_{l}\left(w_{l}\right)=p_{l}\left(w_{h}\right)=1-\frac{t_{l}}{2}, q_{l}\left(w_{l}\right)=q_{l}\left(w_{h}\right)=1, \\
& p_{h}\left(w_{h}\right)=\frac{1+w_{h}}{2}, q_{h}\left(w_{h}\right)=\frac{1-w_{h}}{t_{h}}, p_{h}\left(w_{l}\right)=1-\frac{t_{h}}{2}, q_{h}\left(w_{l}\right)=1 .
\end{aligned}
$$

According to Lemmas 1 and 2,

$$
F_{h}=\frac{\left(1-w_{h}\right)^{2}}{2 t_{h}}=\frac{t_{l}^{2}}{2 t_{h}} \text { and } F_{l}=w_{h}-w_{l}+F_{h}
$$

It can be verified that IC2 is also satisfied. The expected profit of the supplier is

$$
\begin{aligned}
& E\left(Y_{S}\right)=\pi\left(w_{h}+\frac{\left(1-w_{h}\right)^{2}}{2 t_{h}}\right)+(1-\pi)\left(w_{h} \frac{1-w_{h}}{t_{h}}+\frac{\left(1-w_{h}\right)^{2}}{2 t_{h}}\right) \\
& =\pi w_{h}+\frac{(1-\pi) w_{h}\left(1-w_{h}\right)}{t_{h}}+\frac{\left(1-w_{h}\right)^{2}}{2 t_{h}} \\
& =\frac{2\left(1-t_{l}\right)\left[\pi t_{h}+(1-\pi) t_{l}\right]+t_{l}^{2}}{2 t_{h}} .
\end{aligned}
$$

\section{Proof of Proposition 4.}

Here, we prove the results under S5. The results under S10, S15 and S20 can be shown in a similar fashion. Note that in S5, $w_{l}<1-t_{h}$ and $1-t_{l}<w_{h}<1$. According to Equations (3) and (4),

$$
\begin{aligned}
& p_{l}\left(w_{l}\right)=1-\frac{t_{l}}{2}, q_{l}\left(w_{l}\right)=1, p_{l}\left(w_{h}\right)=\frac{1+w_{h}}{2}, q_{l}\left(w_{h}\right)=\frac{1-w_{h}}{t_{l}}, \\
& p_{h}\left(w_{h}\right)=\frac{1+w_{h}}{2}, q_{h}\left(w_{h}\right)=\frac{1-w_{h}}{t_{h}}, p_{h}\left(w_{l}\right)=1-\frac{t_{h}}{2}, q_{h}\left(w_{l}\right)=1 .
\end{aligned}
$$

According to Lemmas 1 and 2,

$$
F_{h}=\frac{\left(1-w_{h}\right)^{2}}{2 t_{h}} \text { and } F_{l}=1-\frac{t_{l}}{2}-w_{l}-\frac{\left(1-w_{h}\right)^{2}}{2 t_{l}}+\frac{\left(1-w_{h}\right)^{2}}{2 t_{h}}
$$

It can be verified that IC2 is also satisfied. The expected profit of the supplier is thus

$$
\begin{aligned}
& E\left(Y_{S}\right)=\pi\left(w_{l}+F_{l}\right)+(1-\pi)\left(w_{h} \frac{1-w_{h}}{t_{h}}+F_{h}\right) \\
& =\pi\left(1-\frac{t_{l}}{2}-\frac{\left(1-w_{h}\right)^{2}}{2 t_{l}}+\frac{\left(1-w_{h}\right)^{2}}{2 t_{h}}\right)+(1-\pi)\left(w_{h} \frac{1-w_{h}}{t_{h}}+\frac{\left(1-w_{h}\right)^{2}}{2 t_{h}}\right) \\
& =\pi\left(1-\frac{t_{l}}{2}\right)-\frac{\pi\left(1-w_{h}\right)^{2}}{2 t_{l}}+\frac{(1-\pi) w_{h}\left(1-w_{h}\right)}{t_{h}}+\frac{\left(1-w_{h}\right)^{2}}{2 t_{h}} . \\
& \frac{d E\left(Y_{S}\right)}{d w_{h}}=0 \Rightarrow w_{h}=\frac{\pi\left(t_{h}-t_{l}\right)}{\pi t_{h}+(1-2 \pi) t_{l}} . \\
& \frac{d^{2} E\left(Y_{S}\right)}{d w_{h}^{2}}=\frac{-\left[\pi t_{h}+(1-2 \pi) t_{l}\right]}{t_{h} t_{l}}<0 . \\
& w_{h}>1-t_{l} \Rightarrow \pi>\frac{1-t_{l}}{1+t_{h}-2 t_{l}}=1-\frac{t_{h}-t_{l}}{1+t_{h}-2 t_{l}} . \\
& E\left(Y_{S}\right)=\pi\left(1-\frac{t_{l}}{2}\right)+\frac{(1-\pi)^{2} t_{l}}{2 t_{h}\left[\pi t_{h}+(1-2 \pi) t_{l}\right]} .
\end{aligned}
$$

\section{Proof of Proposition 5.}

The values of $\pi_{1}$ and $\pi_{2}$ are: $\pi_{1}=\frac{-B_{1}+\sqrt{B_{1}^{2}-4 A C_{1}}}{2 A}$ and $\pi_{2}=\frac{-B_{2}+\sqrt{B_{2}^{2}-4 A C_{2}}}{2 A}$, where

$A=\left(2-t_{l}\right)\left(t_{h}-t_{l}\right)^{2}+t_{l}\left(1-t_{l}\right)^{2}>0, B_{1}=-\left[t_{h}\left(t_{h}-t_{l}\right)\left(2-t_{h}-t_{l}\right)+2 t_{l}\left(1-t_{h}\right)^{2}\right]<0$,

$C_{1}=t_{l}\left(1-t_{h}\right)^{2}>0, B_{2}=t_{h} t_{l}\left(2-t_{l}\right)-2 t_{l}-\left(t_{h}-2 t_{l}\right)\left(2 t_{h}\left(1-t_{l}\right)+t_{l}^{2}\right)<0$, and $C_{2}=t_{l}(1-$

$\left.t_{l}\right)\left(1-2 t_{h}+t_{l}\right)$.

From Proposition 2-4, the following is the local optimal expected profits of the supplier: 


$$
\begin{aligned}
& Y_{S}^{L W S}=1-\frac{t_{h}}{2} \text { (note that the expected profit here is a constant), } \\
& Y_{S}^{F W S}=1-t_{l}+\frac{t_{l}^{2}}{2 t_{h}} \text { (note that the expected profit here is a constant), and } \\
& \left.Y_{S}^{H W S}=\pi\left(1-\frac{t_{l}}{2}\right)+\frac{(1-\pi)^{2} t_{l}}{2 t_{h}\left[\pi t_{h}+(1-2 \pi) t_{l}\right]} \text { (valid if and only if } \pi>\frac{1-t_{l}}{1+t_{h}-2 t_{l}}\right) .
\end{aligned}
$$

A comparison between $Y_{S}^{L W S}$ and $Y_{S}^{F W S}$ finds that

$$
\begin{aligned}
& Y_{S}^{L W S}>Y_{S}^{F W S} \text { if } \pi<\frac{2-t_{h}-t_{l}}{2\left(1-t_{l}\right)}, \\
& Y_{S}^{L W S}<Y_{S}^{F W S} \text { if } \pi>\frac{2-t_{h}-t_{l}}{2\left(1-t_{l}\right)} .
\end{aligned}
$$

A comparison between $Y_{S}^{L W S}$ and $Y_{S}^{H W S}$ finds that

$$
Y_{S}^{L W S}>Y_{S}^{H W S} \text { if } \pi_{1}^{\prime}<\pi<\pi_{1}
$$

where

$$
\pi_{1}^{\prime}=\frac{-B_{1}-\sqrt{B_{1}^{2}-4 A C_{1}}}{2 A} \text { and } \pi_{1}=\frac{-B_{1}+\sqrt{B_{1}^{2}-4 A C_{1}}}{2 A}(\text { as defined in Proposition 5). }
$$

But it can be shown that $\pi_{1}^{\prime}<\frac{1-t_{l}}{1+t_{h}-2 t_{l}}<\pi_{1}<\frac{2-t_{h}-t_{l}}{2\left(1-t_{l}\right)}$. Therefore, $Y_{S}^{L W S}$ is greater than $Y_{S}^{F W S}$ and $Y_{S}^{H W S}$ when $\pi<\pi_{1}$. That is, LWS is globally optimal when $\pi<\pi_{1}$.

A comparison between $Y_{S}^{F W S}$ and $Y_{S}^{H W S}$ finds that

$$
Y_{S}^{F W S}<Y_{S}^{H W S} \text { if } \pi_{2}^{\prime}<\pi<\pi_{2}
$$

where

$$
\pi_{2}^{\prime}=\frac{-B_{2}-\sqrt{B_{2}^{2}-4 A C_{2}}}{2 A} \text { and } \pi_{2}=\frac{-B_{2}+\sqrt{B_{2}^{2}-4 A C_{2}}}{2 A}(\text { as defined in Proposition 5). }
$$

It can be shown that $\pi_{2}^{\prime}<\pi_{1}<\pi_{2}<\frac{2-t_{h}-t_{l}}{2\left(1-t_{l}\right)}$. Therefore, $Y_{S}^{F W S}$ is greater than $Y_{S}^{L W S}$ and $Y_{S}^{H W S}$ when $\pi>$ $\pi_{2}$. That is, FWS is globally optimal when $\pi>\pi_{2}$. Similarly, $Y_{S}^{H W S}$ is greater than $Y_{S}^{F W S}$ and $Y_{S}^{L W S}$ when $\pi_{1}<\pi<\pi_{2}$. That is, HWS is globally optimal when $\pi_{1}<\pi<\pi_{2}$. 